COMENTANDO LO PUBLICADO

\title{
Comentando Laudato Si, de Jorge Bergoglio, 2015. Sobre el cuidado de la Casa Común: una lección de Ecología Integral
}

\section{Estanislao Luis Calabuig}

Departamento de Biodiversidad y Gestión Ambiental. Área de Ecología. Facultad de CC. Biológicas y Ambientales. Universidad de León.

Alabado seas, mi Señor, en todas tus criaturas, especialmente en el Señor hermano sol, por quien nos das el día y nos iluminas.

Alabado seas, mi Señor, por la hermana luna y las estrellas, en el cielo las formaste claras y preciosas y bellas.

Alabado seas, mi Señor, por el hermano viento $y$ por el aire y la nube y el cielo sereno $y$ todo tiempo, por todos ellos a tus criaturas das sustento.

Alabado seas, mi Señor por la hermana agua, la cual es muy humilde, preciosa y casta.

Alabado seas, mi Señor, por el hermano fuego, por el cual iluminas la noche, $y$ es bello y alegre $y$ vigoroso y fuerte.

Alabado seas, mi Señor, por la hermana nuestra madre tierra, la cual nos sostiene y gobierna y produce diversos frutos con coloridas flores y hierbas.

Francisco de Asís. Cántico de las criaturas. 1224.

\section{Introducción}

El 24 de mayo de 2015 se presentaba la Encíclica Laudato Si del Papa Francisco con gran repercusión en los medios de comunicación y en las redes sociales de todo el mundo. En sus propias palabras iba dirigida a cada persona que habita este planeta, frente al deterioro ambiental global. Las reacciones fueron inmediatas, aunque las manifestaciones sobre el fondo plasmado en el documento se expresaron con opiniones de signo muy diferente. Nadie con interés por el medio ambiente podía quedar indiferente. Y sobre todo los dedicados profesionalmente a cualquiera de las temáticas que hoy día abarca esa problemá-

Forma de mencionar este artículo: Luis Calabuig, E., 2016, Comentando Laudato Si, de Jorge Bergoglio, 2015. AmbioCiencias, 14, 91-103. Revista de divulgación científica editada por la Facultad de Ciencias Biológicas y Ambientales de la Universidad de León, ISBN: 1998-3021 (edición digital), 21478942 (edición impresa). Depósito legal: LE-903-07. 
tica, desde los técnicos a los científicos, desde los docentes a los sociólogos, desde los economistas a los políticos, o desde los magnates de las multinacionales hasta los ecologistas, más el pueblo llano de cualquier clase social, región o credo, por el interés en lo que es y representa la persona que firmaba esa carta.

Pocas veces los problemas ambientales han sido defendidos por portavoces tan significados en el ámbito global del planeta. Si Al Gore, premiado en el año 2007 con el Príncipe de Asturias de Cooperación Internacional y el Nobel de la Paz por su claro posicionamiento en la lucha contra el calentamiento global, plasmado en su libro Una verdad incómoda, tras su fallida carrera hacia la Casa Blanca, utilizó un periplo de varios años, un solo documento ha sido suficiente para que Jorge Bergoglio sacudiera a todas las conciencias en favor de la protección de la Tierra (Fig. 1).

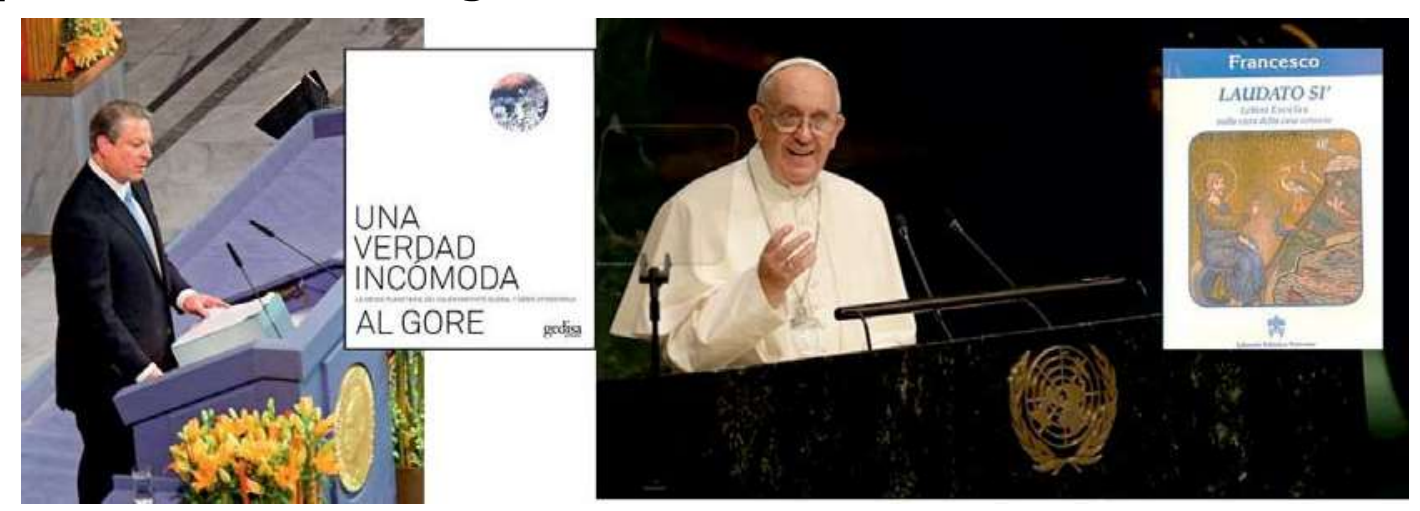

Figura 1. Dos de los más importantes valedores por su lucha contra el cambio global.

Para mí, como universitario y ecólogo en la docencia y la investigación, dedicado a las cuestiones ambientales desde hace algunas décadas, fue una sorpresa comprobar la capacidad de síntesis y el esfuerzo de integración de los conocimientos y avances científicos que se han plasmado en ese documento, para expresar de forma sencilla las implicaciones, efectos y causas del cambio global. Como científico no podía permanecer ajeno ante un manifiesto en el que el término medio ambiente y sus relacionados se citan 162 veces, al igual que las referencias a la ecología con 73 o la mención a los ecosistemas con 24 repeticiones (Fig. 2). Y otros muchos que nos son especialmente cercanos en las disciplinas que se imparten en los grados de nuestra Facultad de Ciencias Biológicas y Ambientales, como biodiversidad, cambio climático, contaminación, impacto ambiental o sostenibilidad. Todas ellas son palabras clave para la descripción de los objetivos que se persiguen en las ciencias que nosotros directamente pretendemos enseñar a nuestros alumnos. Por lo tanto, es casi una obligación analizar esta referencia "sobre el cuidado de la casa común". 


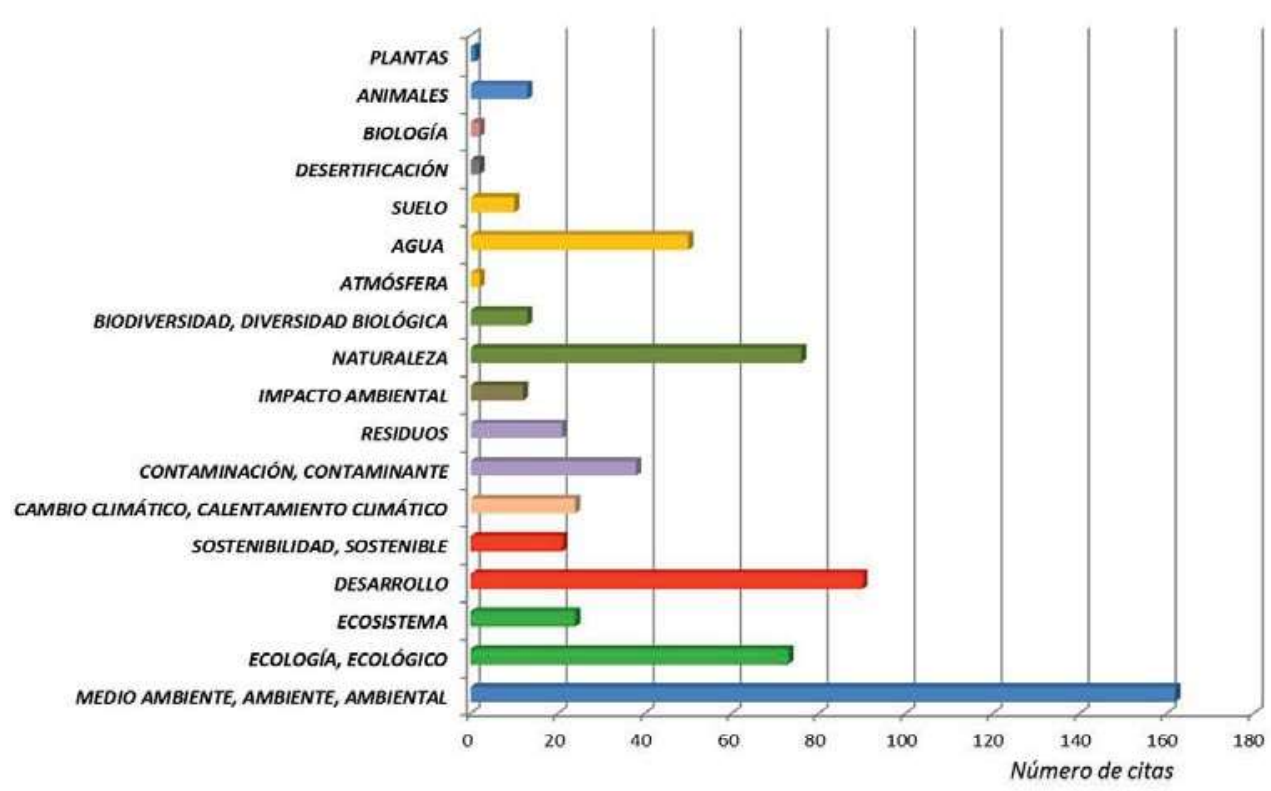

Figura 2. Número de citas de términos clave citados en la Encíclica Laudato Si, relacionados con la problemática ambiental y el cambio global.

Mi acercamiento será exclusivamente desde la perspectiva científica, contrastando las aportaciones conocidas hasta la actualidad en el campo de la investigación de las ciencias ambientales, y su proyección con objetivos de conservación de la naturaleza, resaltando las causas, los efectos y las interacciones propias de todo proceso de desarrollo ligado a la especie humana. Fundamentalmente los comentarios irán dirigidos a lo que se manifiesta en los apartados que conforman el capítulo primero bajo el epígrafe de lo que está pasando a nuestra casa, aunque también dedicaré referencias especiales a lo tratado en el capítulo tercero, dedicado a la raíz humana de la crisis ecológica, y muy especialmente al capítulo cuarto por su planteamiento, conocido como el paradigma de una ecología integral. Sugiero, no obstante, una lectura pausada de la carta en su totalidad, para que aquellos interesados puedan analizarla desde las reflexiones de la filosofía, la ética y la moral, e incluso la religiosa.

\section{Inspiración y motivación}

Esta encíclica, como se manifiesta en el primer párrafo de la misma, está claramente inspirada en el "Cántico de las criaturas" de Francisco de Asís, en el que curiosamente se mencionan como ejes principales los cuatro elementos para explicar los patrones de la naturaleza en el mundo clásico (tierra, agua, aire y fuego), y está motivada ante el clamor por el daño provocado a causa del uso irres- 
ponsable y el abuso sobre los bienes de la Tierra. Se resalta el hecho de que la especie humana ha crecido pensando que era propietaria y dominadora, autorizada a expoliarla y, sin embargo, sus acciones se manifiestan en los síntomas de enfermedad que se advierten en el suelo, en el agua, en el aire y en los seres vivos. Acude a los textos bíblicos para recordar que olvidamos que nosotros mismos somos tierra. Nuestro propio cuerpo está constituido por los elementos del planeta, su aire es el que nos da alimento y su agua nos vivifica y restaura. Copiando las palabras de su antecesor el Papa Pablo VI, presenta la crisis ecológica como una consecuencia dramática de la actividad descontrolada del ser humano, para concluir que debido a una explotación inconsiderada de la naturaleza, la propia especie humana corre el riesgo de destruirla y de ser a su vez víctima de esta degradación. Manifestaciones que no se oyen, por supuesto, por primera vez, sino que han sido pronunciadas en las últimas décadas en los organismos internacionales, como la UNESCO, y repetidas por significados profesionales dedicados a la ciencia. Se alude también en la introducción a algunas causas generales, como las disfunciones de la economía mundial o el seguimiento de modelos de crecimiento que parecen incapaces de garantizar el respeto al medio ambiente.

El principio básico de este manifiesto se centra en que el desafio urgente de proteger nuestra casa común incluye la preocupación de unir a toda la familia humana en la búsqueda de un desarrollo sostenible e integral. Se reconoce que el movimiento ecológico mundial ya ha recorrido un largo y rico camino, y ha generado numerosas agrupaciones ciudadanas que ayudaron a la concienciación, aunque también se pone de manifiesto que las actitudes que obstruyen los caminos de solución van de la negación del problema a la indiferencia, la resignación cómoda o la confianza ciega en soluciones técnicas, sin olvidar que cada persona puede colaborar para enmendar esas disfunciones, cada uno desde su cultura, su experiencia, sus iniciativas y sus capacidades.

\section{Situación ambiental actual}

El capítulo que trata de exponer la situación ambiental recorre los distintos aspectos de la actual crisis ecológica, con el fin de asumir los mejores frutos de la investigación científica actualmente disponible, intentando mirar no sólo los síntomas sino también las causas más profundas. El hilo conductor de la exposición emerge de la convicción de que en el mundo todo está conectado y de la advertencia de la realidad de un mundo limitado y finito. Principios que subyacen en la enseñanza de la ecología si se pretende abordar su estudio a partir de la 
teoría de sistemas, en este caso concreto de los ecosistemas. Se recuerda, muy acertadamente, que si bien el cambio es parte de la dinámica de los sistemas complejos, la velocidad que las acciones humanas le imponen hoy contrasta con la natural lentitud de la evolución biológica. A esto se suma el problema de que los objetivos de ese cambio veloz y constante no necesariamente se orientan al bien común y a un desarrollo sostenible e integral.

Sin embargo la especie humana ha entrado en una etapa de mayor concienciación, caracterizada por una creciente sensibilidad con respecto al medio ambiente y el fomento de pautas para la conservación de la naturaleza, con una sincera y dolorosa preocupación por lo que está ocurriendo con nuestro planeta.

En el texto de la carta se hace un recorrido por aquellas cuestiones que hoy provocan mayor inquietud y que ya no se pueden esconder debajo de la alfombra, con el objetivo de poder reconocer cuál es la contribución que cada uno puede aportar. El primer apartado se dedica a la contaminación y el cambio climático, y empieza por resaltar que la exposición a los contaminantes atmosféricos produce un amplio espectro de efectos sobre la salud humana. Contaminación que afecta a todos, debida al transporte, al humo de la industria, a los depósitos de sustancias que contribuyen a la acidificación de los suelos y del agua, a los fertilizantes, insecticidas, fungicidas y herbicidas. Contaminaciones de muy diversa índole y efectos en distintos ambientes provocados por residuos y desechos peligrosos, muchos de ellos no biodegradables y otros que pueden producir un efecto de bioacumulación.

Problemas que con frecuencia están ligados al derroche, al despilfarro y a la cultura del descarte. Se comenta con algunos ejemplos concretos cómo se desperdicia y se ignora el reciclaje, y cómo eso es contrario al funcionamiento de los ecosistemas naturales, de eficiencia ejemplar si se compara con diversas acciones humanas que al final del ciclo de producción y de consumo, no han desarrollado la suficiente capacidad de absorber y reutilizar residuos y desechos. Habría que limitar al máximo el uso de recursos no renovables, moderar el consumo, maximizar la eficiencia del aprovechamiento, reutilizar y reciclar, pero los avances en ese sentido son todavía muy escasos.

Se aprecia cierta angustia en este relato cuando se entremezclan párrafos que claman porque la Tierra, nuestra casa, parece convertirse cada vez más en un inmenso depósito de porquería. En muchos lugares del planeta, los ancianos añoran los paisajes de otros tiempos, que ahora se ven inundados de basura. Nunca hemos maltratado y lastimado a nuestra casa común como en los últi- 
mos dos siglos. Si alguien observara desde afuera la sociedad planetaria, se asombraría ante semejante comportamiento que a veces parece suicida. Nos recuerdan extraordinariamente las muchas sentencias del jefe indio Seattle de la tribu Suwamish en su carta al presidente de los Estados Unidos de América Franklin Pierce en 1855, que tanto nos gusta relatar a nuestros alumnos, sobre todo cuando, refiriéndose al hombre blanco, pronuncia: "Su apetito devorará la tierra, dejando atrás solamente un desierto".

Se hace especial referencia a la frecuente relación entre las finanzas y la tecnología, con capacidad extraordinaria para resolver problemas concretos, pero en muchos casos incapaz de avistar las múltiples relaciones entre los elementos de la naturaleza creando otros problemas.

Al hablar del clima hace referencia a él como un bien común (recurso de libre acceso), definiéndolo como un sistema complejo relacionado con muchas condiciones esenciales para la vida humana. Y a continuación resalta el consistente consenso científico que indica que nos encontramos ante un preocupante calentamiento del sistema, describiendo sus efectos más significativos de escala global y apelando a la conciencia de todos sobre la necesidad de combatir ese calentamiento, al menos contra las causas humanas que lo producen o acentúan, señalando concretamente las que provocan el incremento de concentración de gases de efecto invernadero provenientes del uso abusivo de combustibles fósiles para desarrollar actividades humanas, o el aumento en la práctica de cambio de usos del suelo, principalmente la deforestación para agricultura. Se comentan también los posibles efectos sobre la disponibilidad de recursos, bienes y servicios imprescindibles, centrando la atención en el agua potable, la energía renovable, la producción agrícola o los impactos sobre la biodiversidad para cualquiera de los niveles de integración biológica, desde el genético al ecológico.

Enfatiza en el hecho de que el cambio climático es un problema con graves dimensiones ambientales, sociales, económicas, distributivas y políticas, y plantea uno de los principales desafios actuales para la humanidad, añadiendo que los peores impactos probablemente recaerán sobre los países en desarrollo, ya que sus medios de subsistencia dependen fuertemente de las reservas naturales y de los servicios ecosistémicos, como la agricultura, la pesca y los recursos forestales. Los cambios climáticos pueden también originar migraciones en plantas y animales que no siempre pueden adaptarse, lo que en ocasiones modifica recursos imprescindibles para las personas, quienes pueden verse obligadas a migrar con gran incertidumbre. Nuestra revista AmbioCiencias publicaba precisamente un artículo sobre migraciones humanas como secuela del cambio global (Doormann ,2012), señalando las zonas críticas para el planeta (Fig. 3). 

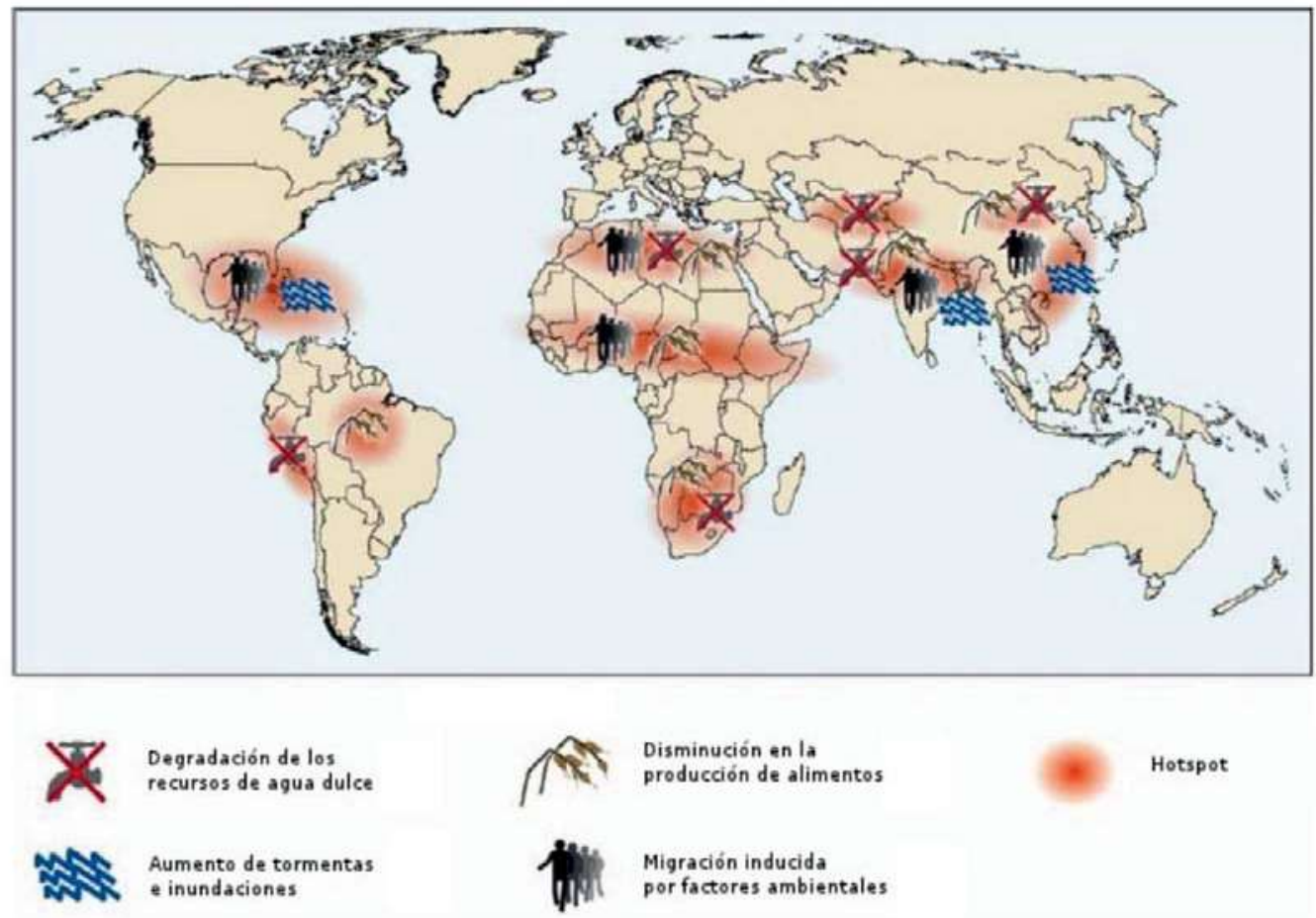

Hotspot

Figura 3. onas calientes del planeta con riego de migración inducida por estresores ambientales. Doormann, 2012 (modificado de Climate Change as a Security Risk. German Advisory Council on Global Change, WBGU. 2007)

La preocupación por el agua es tratada como indicador principal en el apartado crítico de agotamiento de recursos naturales. El agua potable y limpia representa una cuestión de primera importancia, porque es indispensable para la vida humana y para sustentar los ecosistemas terrestres y acuáticos. La provisión del agua permaneció relativamente constante durante mucho tiempo, pero ahora en muchos lugares la demanda supera a la oferta sostenible, con graves consecuencias a corto y largo término. Se podría ampliar este párrafo con la lectura del artículo publicado en la revista AmbioCiencias con tratamiento monográfico sobre lo que es y significa el agua para nuestro planeta y para la especie humana (Luis, 2015). Con perspectiva complementaria, se trata de la pobreza del agua social, para dejar bien claro que grandes sectores de la población no pueden acceder al agua potable segura, o que el recurso del agua se muestra en el planeta con gran heterogeneidad en el espacio y en el tiempo, con fuertes repercusiones sobre todo para los que padecen grave escasez y, sin embargo, se advierte un derroche de agua no sólo en países desarrollados, sino también en aquellos de menor desarrollo que poseen grandes reservas (Fig. 4). Por otra parte, son frecuentes las enfermedades relacionadas con el agua, provocadas por microorganismos o por sustancias químicas. 


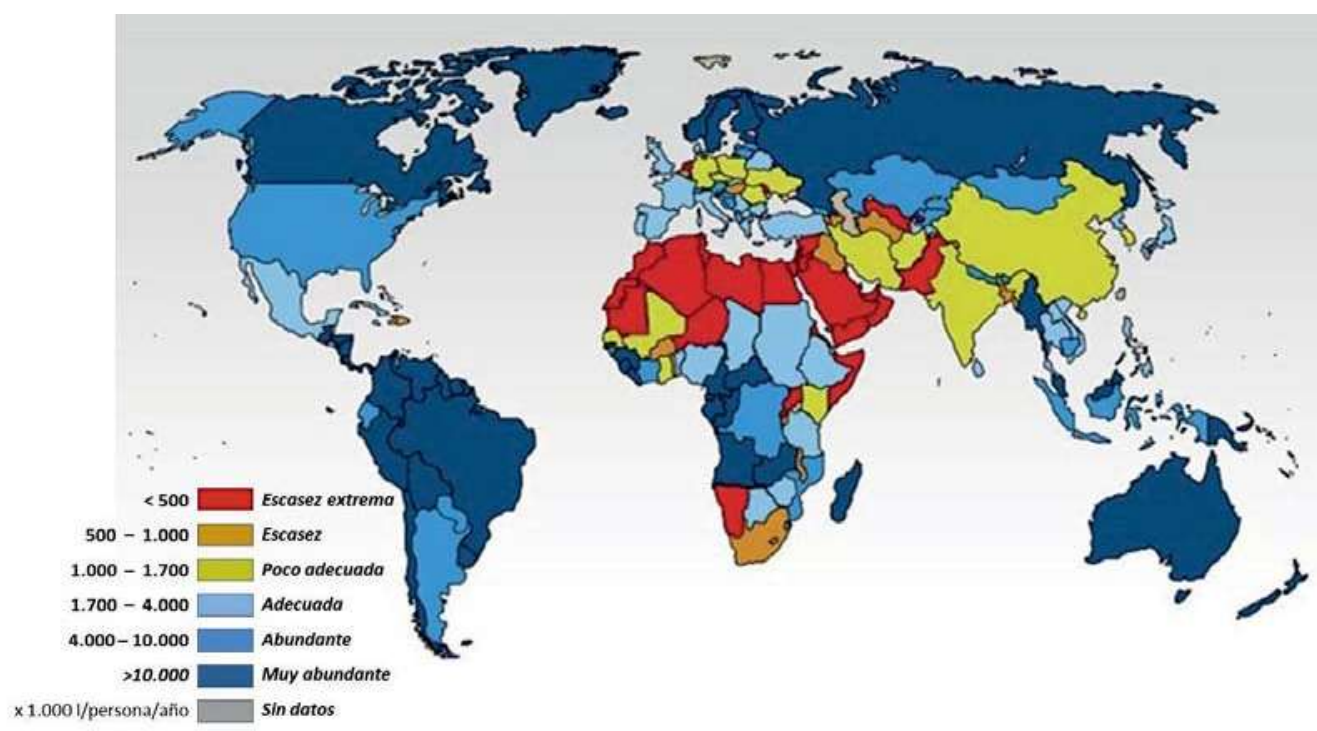

Figura 4. Estimación de la disponibilidad de agua para el año 2025. Fuente: Global Water Initiative. 2005. GEF. International Waters Conference.

\section{Biodiversidad}

Se dedica un apartado a tratar la problemática por pérdida de biodiversidad, reflejada en la desaparición de grandes extensiones de selvas y bosques, que implica al mismo tiempo la pérdida de especies que podrían significar en el futuro recursos sumamente importantes para cubrir múltiples servicios a la humanidad, desde el potencial valor de los genes hasta la capacidad para regular problemas ambientales. Pero no basta pensar en las distintas especies sólo como eventuales recursos explotables, olvidando que tienen un valor en sí mismas. Cada año desaparecen miles de especies vegetales y animales que ya no podremos conocer, que nuestros hijos ya no podrán ver, perdidas para siempre. La inmensa mayoría se extinguen por razones que tienen que ver con alguna acción humana. Se resalta el hecho de la gran subjetividad humana cuando nos inquietamos por la desaparición de alguna especie singular o conspicua, olvidando que para el buen funcionamiento de los ecosistemas todos los organismos son necesarios. Algunas especies poco numerosas, que suelen pasar desapercibidas, juegan un rol crítico fundamental para estabilizar el equilibrio de un lugar.

Las actuaciones en la gestión ambiental, como las aplicaciones preventivas de evaluaciones de impacto ambiental sobre proyectos que implican algún deterioro significativo sobre el medio ambiente, se fijan fundamentalmente en detectar los efectos sobre el suelo, el agua o la atmósfera, pero no siempre se incluye un estudio cuidadoso sobre el impacto en la biodiversidad, como si la 
pérdida de algunas especies o de grupos de animales o plantas fuera algo de poca relevancia. Se hace referencia concreta a la importante reducción de hábitats y a la fragmentación de poblaciones biológicas que pueden aumentar el riesgo de extinción como consecuencia de algunas actuaciones concretas, para pedir a continuación que se busquen alternativas que mitiguen ese impacto, como la creación de corredores ecológicos que puedan mantener la conectividad entre individuos de la misma población biológica. Es necesario invertir mucho más en investigación para entender mejor el comportamiento de los ecosistemas y analizar adecuadamente las diversas variables de impacto de cualquier modificación importante del ambiente.

Se destaca la importancia y los esfuerzos realizados en la preservación de lugares y zonas, tratando de controlar las intervenciones humanas que puedan modificar la fisonomía o alterar la constitución original. Se resaltan los consejos científicos para conservar las zonas del planeta de mayor riqueza de especies o con presencia de endemismos, así como aquellas que constituyen importantes reservas de agua. Se ofrecen como ejemplo de prioridad los pulmones verdes de la Amazonia o la cuenca del Congo, los grandes acuíferos, los glaciares y las barreras de coral.

También puede afectar gravemente a la biodiversidad el remplazo de la flora silvestre por áreas forestadas con monocultivos de árboles, los humedales transformados en cultivos, los manglares costeros sustituidos para otros usos, la sobreexplotación de los recursos pesqueros en los mares, ríos y lagos o el desperdicio por el desarrollo de formas selectivas de pesca en esos mismos ecosistemas, eliminando componentes muy importantes de la cadena alimentaria, y de los cuales dependen, en definitiva, especies que utilizamos para alimentarnos. Debería hacerse un cuidadoso inventario de las especies que alberga cada territorio en orden a desarrollar programas y estrategias de protección, cuidando con especial preocupación a las especies en vías de extinción.

\section{Deterioro de la calidad de vida}

Se reserva un apartado para tratar de la relación entre la degradación ambiental y el deterioro de la calidad de la vida humana y sus efectos sociales, citando como ejemplo la insalubridad de muchas ciudades de crecimiento desmedido y desordenado, con estructuras ineficaces por el exceso en el gasto de energía y agua, con problemas de contaminación de todo tipo y sin suficientes espacios verdes. Por el contario, en otros lugares, se crean urbanizaciones "ecológicas" sólo al servicio de unos pocos con alta disponibilidad económica, donde se 
procura evitar que otros entren a molestar una tranquilidad artificial. Ejemplos de este tipo fueron mencionados en el reciente seminario internacional celebrado en la Universidad de Valladolid, sobre "Corredores ecológicos y planificación espacial” (Fig. 5), dirigido a especialistas en urbanismo (Jiménez, 2016; Holgersen et al., 2015).

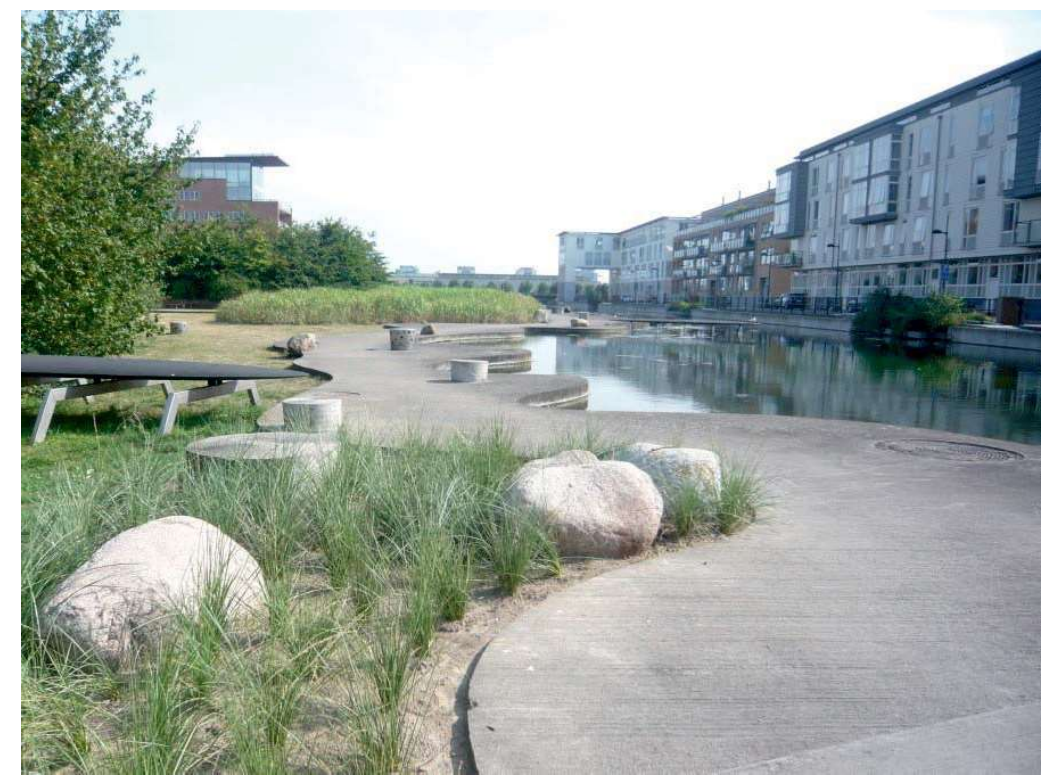

Figura 5. El nuevo diseño "ecológico" de algunas ciudades puede provocar un giro hacia el elitismo social. Foto de M. Jiménez, 2015: Distrito del puerto de Västra en Malmö (Suecia).

\section{Desarrollo sostenible}

El concepto de desarrollo sostenible queda entretejido a lo largo de toda la carta, simplemente para recordar que estamos en la obligación de cumplir con los acuerdos internacionales de la Cumbre de la Tierra de Estocolmo sobre Medio Humano (1972), la Declaración de Nairobi sobre Medio Ambiente (1982) o la Cumbre de la Tierra de Río de Janeiro (1992). Esta última de importantes propuestas de ámbito global sobre gestión ambiental, cambio climático o diversidad biológica, donde se proclamó que los seres humanos constituyen el centro de las preocupaciones relacionadas con el desarrollo sostenible, y donde se aclara ese concepto, surgido del informe preparado para la ONU en 1987 bajo el epígrafe de "Nuestro Futuro Común", y coloquialmente conocido como "Informe Brundtland". Seguramente habrán sido consultados y analizados para la preparación de este texto todos los informes sobre las cumbres mundiales sobre el clima, tuteladas por las Naciones Unidas, desde la de Berlín en 1995, y fundamentalmente la conocida como Protocolo de Kyoto sobre Cambio Climático de 
1997, o documentos igualmente de ámbito global como "La Carta de la Tierra" publicada en el año 2000, auspiciada por la UNESCO, y su antecedente más directo "La Carta Mundial de la Naturaleza" de 1982, ya que en el texto de la encíclica, aunque se reconocen los esfuerzos realizados y las ideas plasmadas en ellos, se enfatiza sobre la debilidad de la reacción política internacional y cómo el sometimiento de la política ante la tecnología y las finanzas se muestra en el fracaso de las Cumbres mundiales sobre medio ambiente. Concretamente se citan en la carta; el Convenio de Basilea (1986) sobre desechos peligrosos, la Convención CITES (1973) sobre el comercio internacional de especies amenazadas de fauna y flora silvestres, la Convención de Viena (1985) para la protección de la capa de ozono y su Protocolo de Montreal con las posteriores enmiendas, y la Conferencia de las Naciones Unidas sobre desarrollo sostenible denominada Río+20 (2012), de la que comenta que emitió una extensa e ineficaz declaración final. Sin embargo siempre hay un resquicio para la esperanza, ya que en la Cumbre de París (2015), mantenida con posterioridad a la publicación de la carta del Papa Francisco, se cierra un acuerdo histórico contra el cambio climático, con el objetivo de marcar la trayectoria para mantener el aumento de temperatura del planeta por debajo de los dos grados centígrados. Se señala específicamente que "mientras se elaboraba esta Encíclica, el debate ha adquirido una particular intensidad".

La preocupación por encontrar soluciones se refleja en toda la presentación de la carta, resaltando mitos cargados de incertidumbre y advirtiendo sobre formas de actuación que pueden complicar el problema. No hay un solo camino de solución, sino posibles escenarios entre el extremo de los que sostienen el mito del progreso y mantienen que los problemas ecológicos se resolverán con nuevas aplicaciones técnicas, y los que entienden que debe impedirse cualquier intervención humana. Se alude repetidas veces al deseo de avanzar en algunas líneas amplias de diálogo y de acción que involucren tanto a cada uno de nosotros como a la política internacional, insistiendo en el hecho evidente de que en el mundo todo está conectado. Sin embargo resalta que muchos de aquellos que tienen más recursos y poder económico o político parecen concentrarse sobre todo en enmascarar los problemas o en ocultar los síntomas, tratando sólo de reducir algunos impactos negativos del cambio climático. Por otra parte, el calentamiento por el enorme consumo de algunos países ricos tiene repercusiones en los lugares más pobres, por lo que sería obligado pensar en una ética de las relaciones internacionales que compensara de forma efectiva esa "deuda ecológica". 